Images dans le monde ibérique et ibéricoaméricain

9 | 2016

Innovations politiques et culturelles dans les pays andins

\title{
Pallai: deshilvanando al cine boliviano digital
}

\section{Andrés Laguna Tapia}

\section{(2) OpenEdition}

Journals

Edición electrónica

URL: http://journals.openedition.org/agedor/1199

DOI: 10.4000/agedor.1199

ISSN: 2104-3353

Editor

Laboratoire LISAA

Referencia electrónica

Andrés Laguna Tapia, « Pallai: deshilvanando al cine boliviano digital », L'Âge d'or [En línea], 9 | 2016,

Publicado el 01 marzo 2016, consultado el 20 abril 2019. URL : http://journals.openedition.org/

agedor/1199; DOI : 10.4000/agedor.1199

Este documento fue generado automáticamente el 20 abril 2019.

L'Âge d'or. Images dans le monde ibérique et ibéricoaméricain 


\title{
Pallai: deshilvanando al cine boliviano digital
}

\author{
Andrés Laguna Tapia
}

1 Fuera de los círculos especializados, el cine boliviano es un gran misterio. Incluso dentro de las fronteras geográficas del país en el que se lo realiza, es poco visto, poco conocido, poco consumido $\mathrm{y}$, por tanto, poco estudiado. Más allá de que existe un grupo cada vez más numeroso de realizadores, un colectivo entusiasta de críticos y académicos que reflexionan en torno a él, existen innumerables dificultades para producir, distribuir y consumir cine boliviano. Imagino que esa es una realidad transportable a buena parte del cine latinoamericano, salvo tal vez a industrias con importantes recursos, con gran capacidad de financiación y de difusión, pienso en el cine mexicano, brasilero y argentino.

2 Por lo general, cuando me presento como historiador y/o crítico de cine boliviano, mis interlocutores se encuentran en aprietos, velozmente rebuscan en su memoria. Con poca frecuencia encuentran algún dato, algún título, algún nombre, alguna referencia, a la tradición fílmica de mi país. La mayor parte de las veces me pasa más o menos lo mismo que cuando me toca hablar de fútbol: un nombre suena y resuena. Cuando la charla va de balones, los pocos aficionados con los que me he cruzado que tienen un conocimiento casi enciclopédico, me hablan de Marco Antonio Etcheverry, el célebre "Diablo", uno de los poquísimos íconos contemporáneos del deporte boliviano, recordado por la frustración de proporciones mundiales que encarnó, más que por cualquier otra cosa. Cuando el diálogo va de imágenes en movimiento, la enorme referencia suele ser Jorge Sanjinés, fundador y cabeza visible del Grupo Kama, pilar del cine indigenista, del cine social, político y de denuncia. De todos los trabajos académicos sobre cine boliviano, con facilidad más de la mitad han sido dedicados exclusivamente a este realizador, al grupo que encabeza y a sus obras. Ha "contaminado"todo discurso relacionado con esta forma de arte en Bolivia, se lo nombra ya sea para reivindicarlo o para defenestrarlo. Aunque pueda resultar incómodo para muchos, es el genuino barómetro del cine boliviano. Por tanto, puede parecer un recurso facilista o gratuito, convocar a este nuestro gran y, a veces obstinado, Achachila, en un texto escrito para una jornada sobre cine digital andino. Para cuestionarme se podría argumentar que, pese a que los aportes de Sanjinés son de gran relevancia, ya sería 
hora de dejar de articular todo discurso entorno a él. Pero lo cierto es que, parafraseando una frase que en la Argentina se usa para Diego Armando Maradona, cuando Jorge Sanjinés se resfría, el cine boliviano estornuda.

3 Para remarcarlo, desde una perspectiva exclusivamente historiográfica, no es posible referirse al cine digital en Bolivia sin mencionar a Sanjinés. Pues, cuando las nuevas tecnologías irrumpieron con fuerza en nuestra tradición fílmica, fue el primer director de la vieja guardia, el primer realizador con un prestigio incuestionable, que renunció a seguir rodando en celuloide. Lo que facilitó algo determinante para el presente del cine boliviano: se dejó de mirar con desdén a las producciones realizadas en un soporte digital. Nunca más se podría asegurar que era el juguete de un grupo de mozalbetes que tenían por hobby hacer peliculitas o que era, meramente, el celuloide para pobres. Cuando el maestro legitimó el soporte, nunca más se lo pudo cuestionar, dio fin con los debates banales en torno a la condición cinematográfica del digital. Su primera película rodada en este soporte, Los hijos del último jardín (2004), es considerada una de sus obras menores. En ella parece no sentirse muy cómodo con el lenguaje singular del nuevo soporte, parece que lo utilizara como un sucedáneo barato del celuloide, sin comprender sus posibilidades, sin sacar provecho de sus fortalezas y sin paliar sus limitaciones. Pero también en esta cinta es muy sugerente el uso de imágenes documentales dentro del relato de ficción, un recurso que evidentemente no es exclusivo del digital, pero que en él se realiza con mayor facilidad y se lograr una unidad estética de manera más fluida. Los hijos del último jardín trata sobre un grupo de muchachos urbanos que, cansados de la situación del país, de la corrupción y del racismo, deciden robar a un político corrupto una cantidad importante de dinero, para entregarlo a los menos favorecidos. Siendo generosos, esta sinopsis suena a Robin Hood en los Andes, pero siendo honestos resulta ser una versión con un grave tenor político de Yamakasi. Les samouraïs des temps modernes (2001) de Ariel Zeitoun y Julien Seri. Indudablemente, lo que la hace interesante está relacionado con el azar, pero también con el ojo del cineasta, con la capacidad para mirar que tiene y con las posibilidades para registrar lo que sucede a su alrededor. Cuando Sanjinés rodaba este largo, casualmente estaban sucediendo los hechos de Febrero Negro de 2003, un momento que marcó un antes y un después en la historia reciente de Bolivia. A raíz de una protesta relativamente violenta de estudiantes del Colegio Ayacucho chicos de no más de 17 o 18 años-, por orden del gobierno, el ejército reprimió a los manifestantes y a la población que estaba en las inmediaciones del centro histórico de la ciudad de La Paz, hasta que francotiradores comenzaron a disparar a matar. Agentes de la Policía Nacional asumieron la defensa de la población civil y se enfrentaron a tiros con miembros del ejército. Ese momento representa simbólicamente el inicio de la crisis del neoliberalismo en Bolivia, la salida de la presidencia de Gonzalo Sánchez de Lozada, y el inicio de la consolidación del proceso que ahora estamos viviendo. Las imágenes que registraron Sanjinés y su equipo son espectaculares, dolorosas y atemorizantes. Pero, más allá de cualquier sensación que nos puedan producir, vale aclarar que son un documento histórico invaluable, así como lo es Las banderas de amanecer (1985), su obra puramente noficcional más importante hasta la fecha. Para un cineasta de las características de Sanjinés, que entiende que el arte es una herramienta para la emancipación social, adoptar al digital como herramienta era el camino evolutivo lógico, pues le permite rodar con eficiencia en prácticamente cualquier condición, sin grandes recursos ni numerosos equipos, sin la necesidad de tener las condiciones óptimas. Le permite hacer cine de batalla en medio de la batalla. Además, le permite elegir formas más éticas de hacer cine en un país con las características de Bolivia, un cine que se desmarque del glamour con el 
que ahora se relaciona al séptimo arte. Curiosamente, Insurgentes (2012) y Juana Azurduy. Guerrillara de la patria grande (2016), hasta la fecha sus últimos largos de ficción, son la antítesis de esos principios, son cintas de gran presupuesto y enorme despliegue de recursos, que sólo fueron posibles gracias al financiamiento proporcionado por un gobierno que suele olvidar a sus cineastas. De hacer un cine de guerrilla, un cine junto al pueblo, pasó a hacer uno casi épico, que roza la propaganda, en el que la forma se disloca del fondo.

Aunque Sanjinés contribuyó a la consolidación del digital, en rigor no fue el primer realizador en utilizarlo. Los historiadores del cine boliviano solemos asegurar que el primer largometraje boliviano rodado en digital en estrenarse en salas comerciales es Dependencia sexual (2003) de Rodrigo Bellott. Este filme es importante no sólo por una cuestión cronológica y por haber borrado la frontera que dividió al audiovisual boliviano por décadas - que separaba al cine del video analógico. Bellott es el primer realizador boliviano en plantear que el digital tiene un lenguaje propio, que de ninguna manera es inferior al del celuloide. En su ópera prima, haciendo uso de pantallas divididas, articuló un discurso visual que intentó expresar la complejidad de las perspectivas de sus personajes. Preocupado por las relaciones sociales mediadas por lo sexual, Bellott encontró en el soporte digital el recurso ideal para expresar sus reflexiones sobre una sociedad falogocéntrica, violenta y compleja. Esta película ratificó lo que algunos otros realizadores ya habían sugerido al menos una década antes, pero no con la contundencia suficiente: hacer cine boliviano que no necesariamente sea indigenista es posible. Hay vida más allá de Jorge Sanjinés y del grupo Ukamau.

En un pasaje del bello libro Arte textil y mundo andino de Teresa Gisbert, Silvia Arze y Martha Cajías, se lee:

Al parecer el tejido andino refleja de alguna manera no sólo el entorno espacial y ecológico. De hecho, en todas las piezas y todos los grupos distinguen la pampa del pallai. La pampa tiene casi la misma acepción que en su contexto geográfico, significa el mundo salvaje - no-cultural - semidesértico. Bertonio la define así: "El campo o todo lo que está fuera del pueblo... la tierra llan". La pampa en el tejido es el sector uniforme, carente de decoración, en contraposición del pallai que es la parte decorada. Viene de la palabra quechua pallay, que es igual que escoger, de la necesidad de escoger hilos para formar una figura. La palabra aimara actual es salta. El pallai representa el mundo cultural con significado. Allí estaba la representación de los dioses y linaje y también está el mundo circundante. En los tejidos actuales hay un paisaje reconocible, tanto por las tejedoras como por los usuarios. ${ }^{1}$

6 Asumamos una postura próxima a las de Jacques Derrida y Roland Barthes. Asumamos que todo texto es un tejido, un textil. Asumamos que el cine es un texto y, por tanto, es un tejido, un textil. Asumamos que, como lo aseguran las autoras citadas en otro pasaje del libro citado, en el mundo andino, en específico en el territorio que hoy conocemos como Bolivia: "Quizá podemos decir que el textil es un mapa o paisaje esquemático."

7 Por tanto, podemos asumir que el cine digital boliviano es una suerte de mapa esquemático que permite transitar por la cultura del país en el que se lo ha realizado. Pero también es un mapa que permite seguir los trazos de los referentes que trascienden la cultura nacional, esos elementos que han contaminado y, a partir de ahí, reconfigurado a lo boliviano. Seamos más específicos, si el textil se divide en pampa, que es lo natural, y pallai, que es lo cultural, podemos afirmar que el cine boliviano registra a la pampa, pero es contenedor del pallai. De esa proposición sale el título de este texto, evidentemente, pero también quiero aprovechar para hacer un homenaje a un bellísimo cortometraje de 
animación que justamente titula: Pallay (2013) dirigido por Patricia Aramayo Mariscal, animado por ella y por Joaquín Cuevas. En él, una tejedora de la etnia jalq'a, decepcionada por el tapiz en el que está trabajando, intenta abandonarlo. Algún tipo de magia se lo impide y la introduce dentro de él. La tejedora se vuelve parte del tejido, del textil, del texto, de su propia obra, pero también de la larga tradición de su pueblo, de su escritura no alfabética. Ahí se encuentra con el Saxra, un ser sobrenatural, que por influencia del cristianismo hoy se lo caracteriza e identifica con el diablo, con el demonio. En un comienzo, la tejedora se resiste al llamado del Saxra, pero después se ponen a bailar juntos, hasta fundirse en una comunión de la que emergen seres fantásticos, las figuras típicas de los hermosos tejidos jalq'a. Hasta que llegan los conquistadores españoles y un sacerdote católico. Ellos comienzan a aniquilar a las creaciones, a los animales míticos. Pero, la fuerza en la que están fundidos la tejedora y el Saxra produce nuevos seres, todavía más imponentes y más fantásticos, que terminan venciendo a la conquista y a la iglesia. Luego, la tejedora sale de ese mundo, del tapiz, vuelve a su lugar de origen, al frente del telar. Ahí observa la obra, ese tejido que es fruto de su comunión con el Saxra, que es el resultado de la superación de una cultura uniformizadora. Observa la escritura no alfabética de su pueblo. Para un boliviano, eso es una suerte de cine dentro del cine. Pallay podría ser una gran y bella metáfora de nuestra tradición fílmica actual, que es fruto de la contaminación de diferentes referentes culturales, de diferentes visiones del mundo, que es un complejo y variado textil, producto de un estado Plurinacional y Multicultural, compuesto por distintas singularidades. Pallay y buena parte de las películas a las que me refiero en este texto, no hacen más que recordarme las enormes pilas de múltiples tejidos que se acumulan en la Cancha, el gigantesco mercado al aire libre de mi ciudad, Cochabamba. Pilas de tejidos forman un nuevo y cada vez más complejo tejido, que no es fácil de leer, pero que seduce como todo texto que en primera instancia parece estar prohibido.

8 Para este trabajo específico, por las características de estas jornadas, mis claves de lectura giran en torno a una triple división del cine boliviano digital, según criterios de producción, propuestas estéticas y tratamiento de temas. División que, como todas, es relativamente arbitraria.

\section{Cine arte, cine de festiva}

Como, ya lo señalé, la primera película filmada en digital, estrenada en salas comerciales es Dependencia sexual (2003) de Rodrigo Bellott y ella fue la primera en entender las claves y las potencialidades del soporte. La pantalla dividida, las múltiples historias cruzadas (que estructuralmente recuerda un poco a Amores Perros, 2000), la reflexión en torno al sexo (un tema incómodo para la cultura boliviana, casi un tabú), el hecho de plantear un cine boliviano que no se remita a historias que suceden en Bolivia y que tiene personajes protagónicos extranjeros, hizo que Dependencia sexual sea una verdadera experiencia iniciática. Con ella comenzó lo que se puede denominar como el cine arte boliviano, de autor, de festival, que encuentra a su espectador ideal en espacios más especializados o académicos.

Incluso un director de una generación anterior, con una carrera respetable, recién pudo permitirse realizar proyectos de corte más autoral después del gesto de Bellott. Juan Carlos Valdivia, que durante décadas se dedicó con mucho éxito a la publicidad y a los video clips, en sus dos primeros largos se limitó a seguir una de las máximas, que según 
Alan Pauls, repetía Gabriel García Márquez en sus talleres de cine en la Escuela de Cine de San Antonio de los Baños: temas latinoamericanos + relato hollywoodense. Fue recién con Zona sur, que se animó a escribir un guión original y a apostar por un lenguaje visual más arriesgado, que en el caso específico de esta película, se podría interpretar como una actualización en soporte digital del célebre plano secuencia integral de Sanjinés.

Siguiendo esa misma estela están realizadores como Martín Boulocq (Lo más bonito y mis mejores años, 2006 y Los Viejos, 2011), Germán Monje (Hospital obrero, 2009) o Eddy Vásquez (El olor de tu ausencia, 2013), que tienen algo de Jim Jarmusch o Tsai Ming-liang, que a partir de historias íntimas, personales, mínimas, nos hablan del país y del ser humano en general. A pesar de que estos realizadores son conscientes de que el único espacio en el que sus obras serán apreciadas es en festivales internacionales, siguen apostando por un arte honesto, que da réditos exclusivamente creativos. Lo que entiendo que es un gesto encomiable y generoso.

\section{El nuevo documental}

Bajo la tutela de Jorge Ruiz y Jorge Sanjinés, el documental boliviano siempre ha sido político, rayando en lo panfletario o, cuando menos, de reafirmación social. Hay pocas cosas que le interesan a casi cualquier boliviano, pero estoy seguro que entre ellas están el fútbol, la cultura entendida como folklore y la política. Por tanto, el documental de la era digital no se ha divorciado del todo de esas constantes. Aunque ha hecho un esfuerzo por reflexionar sobre esos temas con mayor rigor y profundidad. Eduardo López Zabala y Roberto Alem, realizaron dos de las piezas más importantes para repensar la historia del país. En el caso de López en Inal Mama (2010), trata el tema de la coca más allá de los lugares comunes relacionados con el narcotráfico, registra su importancia en la vida cotidiana y, lo que es más interesante, registra la vida cotidiana en torno a la producción de coca. Por su lado Alem, ha producido muchísimos documentos de importancia histórica. En Tentayape (2008), registra a la última comunidad guaraní que intenta mantener sus usos y costumbres "originarios", muestra con contundencia la condición plurinacional y multicultural de la nación, algo casi inédito en un país que había construido una memoria cinematográfica preponderantemente andina y mestiza. Alem develó a la Bolivia más allá de ciertos arquetipos socio-históricos.

Otra muestra de que el documental encarna la vitalidad del cine boliviano digital son coproducciones internacionales como Cocalero (2007) de Alejandro Landes, sobre la campaña que llevó al poder a Evo Morales; El comienzo fue en Warisata de David Busto (2009), sobre una de las poblaciones más combativas y propositivas del altiplano nacional; y Ríos de hombres (2011) de Tin Dirdamal, que desarma algunos de los mitos en torno a la celebérrima Guerra del Agua cochabambina. Cintas relevantes para entender la realidad boliviana y se nutren de la singularidad de la visión de alguien que no ha nacido en Bolivia. La confluencia de distintas visiones, no ha hecho más que enriquecer las múltiples lecturas del país.

Realizadores de documentales que han revolucionado a la tradición fílmica, propositivos y que han firmado algunas de las mejores cintas bolivianas de los últimos años son Diego Mondaca (La chirola, 2009), Álvaro Olmos (San Antonio, 2010) y Miguel Hilari (El corral y el viento, 2014), entre otros, que han entendido que las realidades abigarradas de un país abigarrado merecen y deben ser narradas de la manera más creativa posible. Para narrar 
lo múltiple, lo colorido, lo plural, lo chojcho, buscan un lenguaje similar, que no violenta lo registrado, más bien que se nutre de ello.

\section{Cine $B$, de boliviano}

15 Lo primero que pensamos cuando hablamos de cine andino digital es de lo que en el mercado internacional se podría denominar como cine B, C o, incluso, Z. Es decir, de un cine que no busca ser una verdadera pieza de arte, que no pretende estar en la vanguardia creativa, ni ganar premios en certámenes de prestigio, ni nada parecido. Sus criterios de producción están más próximos a los del mercado, a lo que supuestamente el público consume. Se dice que Roger Corman fue el rey del cine del cine B y que Ed Wood lo fue del cine Z. Si hablamos de un cine B, con "B" de boliviano, tal vez Roberto Calasich podría detener un título equivalente al de los directores mencionados. Se hizo notorio en 1992 con una miniserie de televisión, que se estrenó en la cadena más vista y prestigiosa del país, llamada La bicicleta de los Huanca. En 2007, la reeditó en forma de largometraje, reviviendo su enorme popularidad. Con ella hizo que prolifere un tipo de humor físico, basado en clichés raciales, que tiene poco de políticamente correcto, emparentado con lo que hacen personajes como la mexicana India María (María Elena Velasco Fragoso) o el peruano Cholo Juanito (Raúl Concha Quispe), personajes que provienen de dos de las tradiciones culturales que más han incluido al imaginario boliviano. Este registro se extiende a otro de los grandes éxitos de este realizador, Faustino Mayta visita a su prima (2003), que trata de manera sorprendentemente jocosa el tema de la semi esclavitud en la que viven muchos migrantes bolivianos en Buenos Aires. Aunque ha buscado diversificar su registro con su película La sirena del lago (2012) y con un proyecto que intenta terminar desde hace años sobre la Guerra del Pacífico de 1879, Calasich sigue siendo uno de los representantes del humor costumbrista boliviano. Tiene por gran mérito realizar un cine muy popular, que ha gestionado con gran éxito la distribución en los mercados informales y en los canales alternativos de distribución. Pero existen aspectos de su obra que son altamente cuestionables, pues suele retratar al indio y al campesino como seres meramente ignorantes y semi civilizados. Suele normalizar al racismo, a la delincuencia, a la violencia de género, a las violaciones, hasta llegar a hacer apología de ellas.

A pesar de ello, como lo afirmaba, el cine de Calasich y su sentido del humor son tremendamente influyentes hasta el punto de que directores bolivianos de prestigio como Paolo Agazzi y Rodrigo Bellott, han reinterpretado su tipo de cine en dos películas importantes para el cine boliviano, que han legitimado a la comedia popular y que exploraron los límites técnicos del digital. Sena Quina (2005) de Agazzi y ¿Quién mató a la llamita blanca? (2006) de Bellott fueron grandes éxitos de taquilla y comparten una propuesta similar. Sus elencos están llenos de actores salidos del café concert y del teatro popular, gente relativamente conocida en el país; sus estructuras narrativas son de road movie; tienen claves de comedia fácil, con mucho humor físico y gags influidos por la escuela Chespirito ${ }^{3}$; $y$, lo que me parece más interesante, ambas utilizan animaciones, inter títulos, pantallas múltiples y una serie de múltiples recursos que recargan la propuesta visual, buscan aproximarla a la estética chojcha urbana, una estética que coquetea con lo kitsch, en la que lo supuestamente andino está tan exacerbado hasta el punto de parecer psicodélico.

17 Lo que intuyo, es que las manifestaciones más sugerentes de cine $\mathrm{B}$ o $\mathrm{Z}$ boliviano, no salen de directores más o menos consagrados. Como ha sucedido en el Perú, la popularización 
de las nuevas tecnologías ha permitido que se ruede en las provincias, en zonas que no tenían una tradición fílmica por sus condiciones socioeconómicas. En Bolivia, aunque en proporciones menores que en Perú o Ecuador, ha proliferado lo que podría denominarse como un cine rural o de provincia, un cine producido y distribuido en espacios lejanos a las ciudades o periurbanos. El documentalista Miguel Hilari al respecto apunta:

En Bolivia, al igual que en Ecuador y en todo el territorio de los Andes, hay ciertas películas que se mueven fuera del gremio de los cineastas y de sus modos de producción, fuera de las regulaciones del estado y del mercado formal de exhibición en salas comerciales. Estas películas responden a distintos modos de producción y son exhibidos a través del mercado informal de DVDs. Han habido muchos intentos de denominar este cine, desde "amateur" y "bajo tierra" en Ecuador, a "cine de provincia" en Perú o "cine rural" en Bolivia. ${ }^{4}$

Como lo reconoce el guionista y crítico de cine Gilmar Gonzáles:

Es muy interesante el fenómeno que se da con estas películas, pues al carecer de cualquier tipo de marketeo producen una curiosidad enorme en el espectador, especialmente si tiene que realizar un viaje de dos horas de vuelta a la ciudad con el paquete en las manos. Es claro, hay signos estilísticos que uno ya presupone y que caracterizan estas producciones. Larguísimas duraciones (tres a cuatro horas), la utilización sintomática de planos muy largos, desconocimiento del fraccionamiento montajístico, la elaboración detallada de los disfraces, que ya se hace presente en las muchas películas de condenados, y la proliferación de escenas cómicas de borracheras reales, actores borrachos representando, o intentando representar, sus papeles. $^{5}$

18 Así como sucede en otras tradiciones, en estas películas suele haber una comunión entre la cotidianidad más pedestre con los ritos y mitos de las culturas andinas ${ }^{6}$. Estas películas están hechas con el pallai. Uno de los ejemplos más populares y relevantes de este cine rural es el El Zorro y la Pastora, de difícil datación, realizada en Tomoco Chico, provincia Camacho, en el departamento de La Paz. Hilari escribe sobre ella:

El Zorro y la Pastora ha sido filmada por un camarógrafo al que literalmente se le escucha respirar detrás de la cámara, el sonido está plagado de interrupciones por el viento, y el material parece estar editado en cámara, lo que significa que las dos horas y media de duración son todo el material filmado. En ese caso se habría filmado en orden secuencial sin repetir tomas. ${ }^{7}$

19 Este no intencional experimento estilístico, no sólo es sugerente por lo formal, sino porque se basa en los mitos de la región y recupera como personaje principal al Zorro Antonio, ser fantástico que constantemente burla al hombre y que permite la construcción de un relato en el que el humor y la tradición se conjugan. En un territorio intermedio de las películas rurales de terror peruanas y de una película de George Romero, está otro buen ejemplo, La cholita condenada por su manta de vicuña de Jaime Franz Machaca Paye y Walter Machaca Paye. Cuenta la historia de una mujer que vuelve del más allá para cobrar venganza, pero ella es casi un zombie, un ser con poderes que recuerdan en algo a The Crow de James O'Barr. Por su presencia en sitios como YouTube, esta película está adquiriendo el rotulo de cinta de culto. Como asegura Gonzáles: "Al ver estas películas marginales ya no se observa solamente la pantalla, sino sistemas de producción, sistemas de pensamiento." ${ }^{8}$

Es pertinente apuntar que es un hecho es que en los países andinos, lo rural está en constante interrelación con lo urbano, son espacios que se contaminan mutuamente. El boliviano, viaja del campo a la ciudad, pero no es un camino sin retorno, hay una dinámica de idas y vueltas innumerables, que reconfiguran el ser de quienes las experimentan. El crítico de cine Santiago Espinoza hace un importante apunte: 
Una primera intuición es que en las películas bolivianas del último tiempo se consuma un viaje de retorno al mundo rural andino, pero que no es definitivo: se vuelve para conocerse, encontrarse, pero con la sospecha de que no se puede vivir de forma permanente y exclusiva en el campo. La migración ya no es solo de ida. La vuelta no es definitiva. La Bolivia de hoy, en franco proceso de urbanización, pero aferrada a un imaginario y discurso reivindicativo de lo rural, parecen decirnos estas películas, exige circular, entrar y salir, conectarse con lo ancestral y con lo moderno, tensionarse y, solo recién, asumirse como sujeto. ${ }^{9}$

24 Algr facilidad que envidia cualquier artista de otros géneros o cualquier industria. En ese sentido, aunque no es rigurosamente una industria cinematográfica, uno de los registros audiovisuales que mejor refleja estas dinámicas son sus videoclips, en específico, me interesa hacer mención a los de un género musical específico: el huayño zapateado. Este tipo de música, probablemente originaria del Norte de Potosí, con fuertes relaciones con la cumbia andina, es un fenómeno complejo, al que no podemos hacer referencia en este 
texto por cuestiones de enfoque, tiempo y espacio, pero me interesa mencionar que su soporte visual comparte muchísimos elementos con el cine marginal al que se ha hecho referencia en párrafos anteriores. Realizadores como Edwin Apaza Roque de Gigante producciones o Wilson Ramírez, director de Banana Records, ganando experiencia han logrado llevar a imágenes el discurso del huayño zapateado, un género musical que habla de amor y de pasiones, de las relaciones de poder y de género, de la migración nacional e internacional, de la cultura boliviana, del pallai. En una entrevista que Sergio de la Zerda la hizo a Ramírez apunta:

En algunos casos tratamos de armar una especie de telenovela en los videos. Hemos tenido que contratar a parientes de los artistas por la timidez de estos últimos. Hoy el oficio se ha vuelto más fácil porque las cantantes se desenvuelven tan bien que entran en un proceso natural. ${ }^{10}$

En ese proceso han desarrollado una distintiva estética:

Para los efectos hacemos tomas de cromado, lo cual se ha puesto muy de moda. Los artistas siempre han formado parte de la producción. Ahora son ellos quienes arman sus tramas porque ya tienen mayor confianza y han aprendido mucho, a tal punto que se les entrega cámaras para que graben los lugares que visitan en países extranjeros. La empresa luego rescata algunas imágenes para aumentarlas a los videos en edición y mostrar que la música indígena está trascendiendo fronteras. ${ }^{11}$

Estos videos tienen una enorme difusión en canales como YouTube, se han convertido en una genuina muestra de cómo el soporte digital se ha puesto al servicio de la complejidad y de la multiplicidad de la cultura boliviana. Son una paradoja, a la vez rurales y urbanos, locales y globales, marginales y representantes esenciales de la producción cultural boliviana.

El cine boliviano, el audiovisual boliviano, durante décadas, en especial a partir de la figura de Sanjinés, desde que el indigenismo se impuso como escuela dominante, ha buscado un lenguaje visual que contenga a la cosmovisión andina. Se puede debatir si lo ha logrado o no. Lo que me parece indudable es que, aunque haya proliferado la falta de rigor y que las producciones mediocres sean numerosas, el digital ha permitido que el cine boliviano sea más complejo, polisémico y polimorfo. Hoy todo el cine boliviano es digital. Y casi todo, por falta de apoyo estatal o privado, por falta de industria, es marginal. Por tanto, cada vez se parece más al país y a la cultura que registra, a ese pallai que no deja de tejerse y destejerse.

\section{NOTAS}

1. GISBERT Teresa, ARZE Silvia y CAJÍAS Martha, Arte textil y mundo andino, La Paz, Plural Editores, 2006, p. 33.

2. Ibid., p. 19.

3. Chespirito fue el nombre artístico de Roberto Gómez Bolaño (1929-2014), cómico mexicano que fue enormemente popular en Latinoamérica gracias programas de televisión protagonizados por personajes de su creación como el Chavo del 8 y el Chapulín Colorado, entre otros. De humor sencillo, se caracterizaba por repetir bromas guionizadas en contextos distintos o con mínimas variantes, por lo general, reposando en clichés raciales, regionales o sociales. 
4. HILARI Miguel, “Cine y leyendas: La emergente producción rural”, Texto inédito, leído en VII Congreso de la Asociación de Estudios Bolivianos, realizado en Sucre, del 29 de julio al $1^{\circ}$ de agosto 2013.

5. Gonzáles II, Gilmar, "Laimes contra Qaqachacas zombis" in La Prensa, 01/07/2012, [http:// cineypunto.blogspot.fr/2012/07/laimes-contra-qaqachacas-zombis.html].

6. Estas experiencias pueden estar relacionadas, o por lo menos pueden ser comparadas, con el trabajo que hace el Centro de Formación y Realización Cinematográfica (CEFREC), fundado en 1989, que desde 1996 y con apoyo de la cooperación española, se dedica a la formación de comunicadores indígenas seleccionados por organizaciones indígenas de presencia nacional, como la Confederación Sindical Única de Trabajadores Campesinos de Bolivia, la Confederación de Comunidades Interculturales de Bolivia, la Confederación de Indígenas del Oriente Boliviano o el Consejo de Ayllus y Markas del Qullasuyo. Los comunicadores formados dieron vida a su propia organización, denominada Consejo Audiovisual Indígena Boliviano (CAIB). Generalmente, los productos del CEFREC son de difícil acceso, de distribución restringida, pero uno de los pocos a los que se puede acceder, que se encuentra en el mercado pirata y en Internet, justamente parece precursor del cine rural al que estamos haciendo referencia. El cortometraje Q'ati q'ati dirigido en 1993 por Reynaldo Yujra (que fue protagonista de La nación clandestina, 1989, de Sanjinés), tuvo un apoyo de 5000 dólares de la Cooperación Española, lo que lo separa en criterios de producción, desarrolla un relato de terror que se nutre de elementos de la cultura andina y de sus mitos, lo que es un gesto germinal.

7. HILARI, Miguel, “Cine y leyendas...”, op. cit.

8. Ibid.

9. ESPINOZA, Santiago, «Miradas que migran. La interacción campo-ciudad en el cine boliviano reciente" in Ramona, periódico Opinión, 26/07/2015, [http://www.opinion.com.bo/opinion/ ramona/2015/0726/suplementos.php?id=6837].

10. DE LA ZERDA Sergio, “De 'Cholita Marina' a la construcción de relatos: La Historia Detrás del Videoclip" in De Bolivia con amor: el huayño zapateado, Cochabamba, Ramona Editores/Gobierno Autónomo Departamental de Cochabamba, Secretaría Departamental de Desarrollo Humano Integral Dirección de Culturas e Interculturalidad, 2013, p. 34.

11. Ibid., p. 36.

\section{RESÚMENES}

Desde sus inicios, el cine boliviano logró ser una manifestación creativa de relevancia. Gracias a las nuevas tecnologías y a la posibilidad de realizar películas en digital, el panorama se ha complejizado de manera radical en este siglo. Se ha propiciado una verdadera "explosión demográfica" y una diversificación importante de discursos estéticos y temáticos. El abaratamiento de costos de producción, el mayor acceso a información especializada, la utilización de redes sociales y de canales no oficiales de distribución, se han convertido en las grandes herramientas de un nuevo cine boliviano. Es un cine mestizo, cholo, lleno de referencias no evidentes, que no deja de dialogar con sus orígenes, pero que no se rige por los formatos convencionales, que trasciende las fronteras nacionales, que tiene un discurso que parece surgir de la dinámica de la supervivencia y de la necesidad de dar testimonio de vidas que están en los márgenes de la sociedad oficial. 
Depuis sa création, le cinéma bolivien a réussi à exceller en tant que manifestation artistique. Mais depuis le début du siècle, grâce aux nouvelles technologies et à la possibilité de tourner des films en numérique, la situation est devenue beaucoup plus complexe. On observe en effet une véritable "explosion démographique " ainsi qu'un foisonnement de discours esthétiques et thématiques. La diminution des coûts de production, la démocratisation de l'accès à une information spécialisée ainsi qui l'utilisation des réseaux sociaux et des canaux de distribution informels sont devenus les principaux ressorts du nouveau cinéma bolivien. Il s'agit d'un cinéma métis, «cholo ", rempli de références souterraines, qui ne cesse de dialoguer avec ses origines, mais qui ne se plie pas aux formats conventionnels, qui transcende les frontières nationales et qui propose un discours s'appuyant sur une dynamique de survie ainsi que sur la nécessité de proposer des témoignages de la vie aux marges de la société officielle.

\section{ÍNDICE}

Mots-clés: cinéma bolivien, cinéma numérique, cinéma d'auteur, documentaire, cinéma marginal

Palabras claves: cine boliviano, cine digital, cine de autor, documental, cine marginal

\section{AUTOR}

\section{ANDRÉS LAGUNA TAPIA}

Universidad Privada Boliviana, Cochabamba 